\title{
Determinants of Poverty in Albania
}

\author{
Alma Spaho \\ Faculty of Economy, University of Tirana, Albania \\ e-mail:alma.spaho@unitir.edu.al
}

\section{Doi:10.5901/jesr.2014.v4n2p157}

\begin{abstract}
Poverty is a widespread phenomenon in all over the world. Measurement and analysis of poverty is needed to identify the poor, the nature and extent of poverty and its determinants, and to assess the impact of policies and welfare programs on the poor. Based on Albania Living Standard measurement Surveys (LSMSs) data, after an overall improvement of the main indicators measuring the poverty from 2002 to 2008, the percentage of population living in poverty has increased by $15.4 \%$ from 2008 to 2012 (INSTAT and World Bank, 2013). The results of LSMS 2012 data indicated an increase of poverty in both urban and rural areas, and the increase was higher in urban area. The aim of this study is to identify the determinants of poverty in Albania, at the household level using a questionnaire. The objectives of this research were: to measure the level of poverty of the sample population, to determine the potential factors that impact poverty and to evaluate their impact on the level of the household's welfare and poverty status of the household using econometric modeling. The data were collected during November 2013, and direct interviews were conducted with 215 households living in rural and urban area. Two regression models were estimated based on the collected data, a log-linear model with the logarithm of per capita monthly consumption as the dependent variable and a logistic model with poverty status as the dependent variable, and a set of economic and demographic variables as the explanatory variables. It was found that the variables that impacted the per capita consumption of the household and the poverty status of the household were household size and residence. Poverty alleviation efforts should be made to improve the social and demographic characteristics of the households, since the number of the poor is increased in both urban and rural areas. To reduce poverty, great attention must be paid to the manufacturing sector, agriculture and tourism.
\end{abstract}

Keywords: household, consumption, headcount, econometric modeling, Albania.

\section{Introduction}

Poverty is a multidimensional and complex phenomenon and is related not only to the income or consume, considered as monetary dimension of poverty, but also to non-monetary dimensions such as education, health, gender equality, water supply, etc. Poverty is caused by many factors and brings several effects which influence the lives of people considered to be poor. The influence of the factors varies from one place to another, because many countries have different development possibilities. The influential factors of poverty level are not only economical, but also social, political, cultural, geographical, etc.

Measurement and analysis of poverty is needed to identify the poor, the nature and extent of poverty and its determinants, and to assess the impact of policies and welfare programs on the poor. In general, poverty can be expressed as deprivation in well-being. Poverty can be defined both in terms of income deprivation and inadequacies in a number of non-income measures of welfare such as education, health and access to basic services and infrastructure. The focus of this paper was the absolute poverty. Absolute poverty is defined as the inability of people to meet their basic needs. A measure of absolute poverty is the headcount index rate, which indicates the number of people below the poverty line. There exists different line of poverty. For the situation of Albania, where the extension of the informal sector makes the estimation of incomes difficult, more adequate is the poverty line based on consumption expenditures. The poverty line in Albania has been estimated equal to 4,891 Lek per capita per month. A household is considered as poor if its per capita consumption expenses falls bellow a minimum level (poverty line) necessary to meet the basic food and non-food needs.

Economic and social development is necessary for achieving poverty reduction. Sustained high rates of economic growth are a prerequisite to reduce poverty. Albania economic growth slowed down sharply in 2012. Following an average real GDP growth rate of $3.4 \%$ in the preceding three years, the Albanian authorities estimate that annual real GDP growth was 1.6\% in 2012 (European Commission, 2013). The slowdown reflects low consumption. In 2012, the 
mean per capita real consumption was decreased by $8 \%$ compared with 2008, from Lek 9,731 in 2008 to Lek 8,939 in 2012 (INSTAT and World Bank, 2012).

After continuous reduction of poverty from 2002 to 2008, the LSMS 2012 data indicated an overall increase of poverty in Albania from 2008 to 2008 and the increase of poverty was higher in urban area (INSTAT and World Bank, 2013). To develop strategies for poverty reduction must be identified the factors that are strongly associated with poverty and that could be influenced by policy changes. The determinants of poverty can be macroeconomic or microeconomic. This study was concerned with microeconomic variables and characteristics.

The aim of the study was the identification of the factors influential on household poverty in Albania, by using a recent questionnaire. In this study the factors affecting poverty were analyzed with respect to two econometric models. The objectives of this research were: to measure the absolute poverty rate, and to identify the determinants of absolute poverty of household in Albania.

\section{Poverty Trends in Albania According to LSMSs Data}

After an overall improvement of the main indicators measuring the poverty from 2002 to 2008 , the headcount rate index, reported as percentage of population whose real per capita monthly consumption falls below the poverty line (Lek 4,891) was increased by 15.4\% from 2008 to 2012 (from 12.4\% in 2008 to 14.3\% in 2012) (INSTAT and World Bank, 2013). While in 2008, roughly 200,000 out of about 575,000 poor people in 2005 were lifted out of poverty, around 30,000 people had fallen in poverty in 2012 (from 373,000 poor people in 2008 to 402,000 poor people in 2012).

The analysis of poverty by area of location, from 2002 to 2005 , indicated the reduction of poverty by $42.5 \%$ in urban area and about 18\% in rural area. From 2005 to 2008 the urban headcount poverty rate decreased by 10\%, whereas the rural headcount poverty rate decreased by around 40\%. The results of LSMS 2012 survey data analysis indicated that poverty was increased in both urban and rural areas, and the increase was much higher in urban area. The headcount rate of poverty was increased from 14.6 in 2008 to 15.3 in 2012 in rural area and from 10.1\% in 2008 to $13.6 \%$ in 2012 in urban area. The headcount poverty rate was reduced more in the rural Mountain areas (INSTAT and World Bank, 2013).

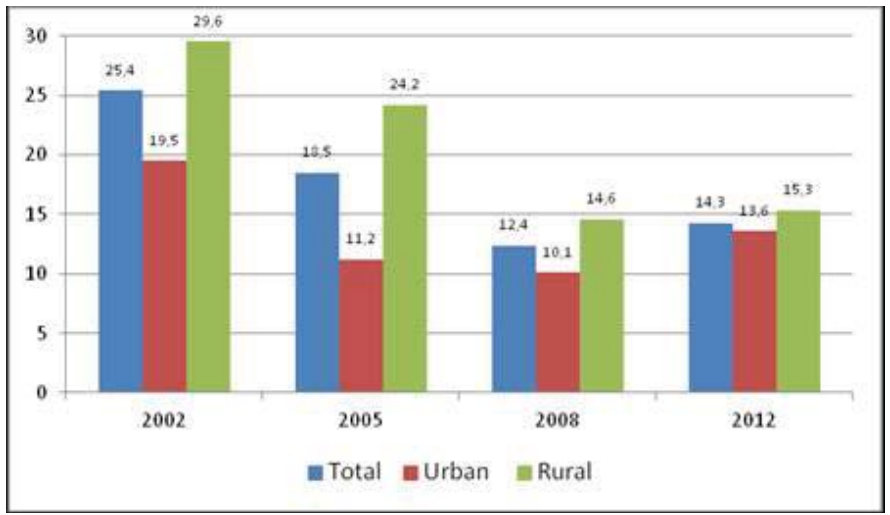

Figure 1. Incidence of poverty trends (Source: INSTAT database)

Based on LSMS 2002 and LSMS 2005 data, the rank of the strata according to the poverty rate was: Mountain, Central, Coastal and Tirana. The decrease of poverty was larger in Tirana (more than 50\%) and Mountain (about 40\%), followed by Coastal (about 20\%) and Central (17\%). Comparing 2005 and 2008 surveys results, the Central has had the largest reduction of poverty (about 50\%), followed by Coastal, whereas the Mountain has experienced a slight increase in poverty, widening the distance with other areas. The rank of strata according to the poverty rate in 2008 has changed to: Mountain, Coastal, Central and Tirana. In 2012, the Mountain has had a sharp decrease in poverty by $42.5 \%$ compared to 2008. This reduction in poverty possibly was a consequence of the movement of the population and the continuous movement of the Mountain population toward other regions. Tirana has had the highest increase in poverty by $44 \%$ from 2008 to 2012, followed by Coastal with 35\% and Central by around 17\%. In 2012, the rank of strata according to the poverty rate was: Coastal, Mountain, Central, and Tirana. 


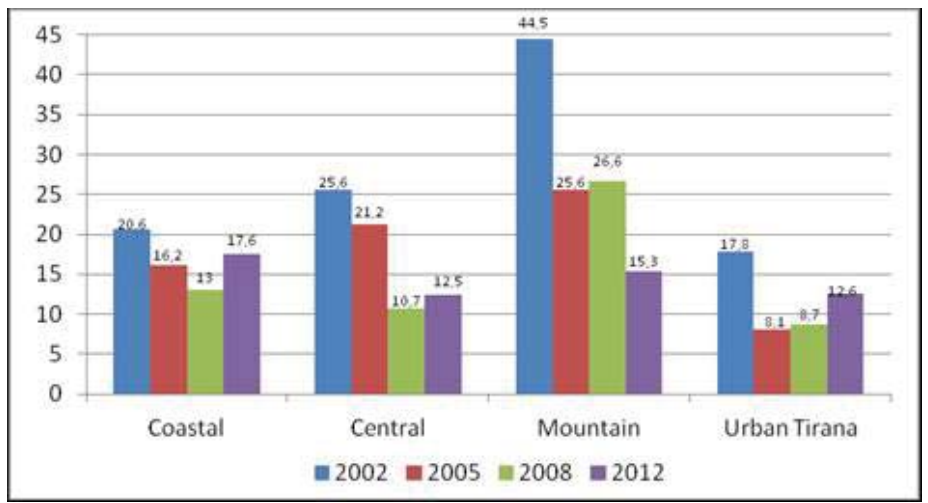

Figure 2. Incidence of poverty by strata (Source: INSTAT database)

The mean per capita real consumption was Lek 7,801 in 2002, Lek 9,105 in 2005 and Lek 9,731 in 2008. The mean per capita consumption was increased by $16 \%$ from 2002 to 2005, by $7 \%$ from 2005 to 2008, evidencing an improvement in the welfare of the country. In 2012, the mean per capita real consumption (with 2002 year prices) was decreased by $8 \%$ compared with 2008, from Lek 9,731 in 2008 to Lek 8,939 in 2012, indicating a deterioration of country welfare.

Table 1. Consumption expenditures patterns by main groups

\begin{tabular}{cccccc}
\hline & Food & Nonfood & Utilities & Education & Durables \\
\hline 2002 & 4,906 & 1,655 & 958 & 177 & 105 \\
2005 & 5,160 & 2,457 & 1,087 & 275 & 128 \\
2008 & 5,280 & 2,519 & 1,447 & 432 & 56 \\
2012 & 5,047 & 2,013 & 1,482 & 338 & 59 \\
\hline
\end{tabular}

Source: INSTAT database

Considering the absolute value (in Lek) of the per capita expenditures per month, form 2002 to 2005 the Albanian households have increased more the expenditures for education (55\%) and non-food consumption (49\%), and also have increased (but less) the expenditures for durables (22\%), utilities (14\%) and food expenditures (5\%). This is an important indicator of welfare improvement in Albania. From 2005 to 2008, Albanian households have increased the expenditures for education (57\%) and utilities (33\%). The increase in the education expenditures indicated a higher quality of life in Albania. The increase of poverty, from 2008 to 2012, was accompanied by a decrease in consumption expenditures for education (21.8\%), non-food (20\%), and food (4.5\%), and a slight increase in the expenditures for durables (5.3\%) and utilities (2.4\%).

\section{Literature Review}

Poverty still is a critical problem threatening the whole world, and researchers in both developed and developing states have largely been interested in this issue. Many researchers have focused on their studies to the factors affecting poverty in addition to determining its limits. A number of studies have studied the factors that can contribute to one's poverty status, either using the characteristics of the household as a whole or that of the household head as possible determinants of household poverty. Household level determinants of poverty generally rely on the household level data. Age, gender of the household head and educational level are generally found to be the most important determinants of poverty. Sekhampu (2013) using logistic regression analysis to identify the factors influencing household poverty status found that household size, employment status and age of the household head were significant predictors of poverty. Cuesta-Nepo and Pizzolito (2011) showed that with respect to absolute poverty limit, the effective factors on poverty were age, gender and the level of education. In their study, Achai et al. (2010) concluded that educational attainment of the household head and residence were important variables explaining the poverty. Fouareg and Layte (2003), in their 
research exhibited that education level and the numbers of household members were effective on poverty. Geda et al. (2001), in their study about absolute poverty in Kenya, found that the residence, gender, the sector of employment of the head of household, education level and household size affected poverty.

Most of the studies about poverty in Albania rely on the expenditure and consumption data and thus use the poverty line computed from the Albania Living Standards Surveys data using the cost of basic needs method. While literature on poverty measurement is by now relatively developed and abundant, there are very few studies dealing with finding the determinant or causes of poverty. In the report of World Bank (2003) about poverty in Albania, results of multivariate analysis using LSMS 2002 data confirmed high correlations between education, higher shares of members with secondary and higher, large households, number of children, share of family members unemployed and poverty. In their study, Audet et al. (2006), using LSMS 2002 data, found that the education level of the household's head, household size and residence were significant factors explaining poverty in Albania. In the report of World Bank (2007), using LSMS 2005 data, was found that poverty was correlated with household size, age and education. Mastromarco et al. (2010), using LSMS 2005 data, found high correlations between gender, low education level, household size and poverty. Myftaraj (2011) using LSMS 2008 data, found the following variables as the key determinants of poverty: household size, residence, education level and age of household head.

\section{Research Methodology}

The study population consists of families living in Tirana, Durrës and Korça. Using a simple random sampling, 215 families living in urban and rural areas was completed a questionnaire during November 2013. In the questionnaire were included questions about demographics characteristics of the household head such as age, gender, education level, employment status and the sector of employment, and family data such as household size, residence, average monthly income and average monthly consumption expenditures. Also they were asked if they consider themselves poor or nonpoor.

Two econometric models were estimated, a log-linear regression model and a logistic regression model on the potential determinants of poverty in terms of household's characteristics. The dependent variable of log-linear regression model was the logarithm of per capita household total consumption expenditures. There exists considerable debate about whether to use income or consumption to measure household welfare. The economy of Albania is largely rural and income is not accurately measured, so income poverty in Albania is estimated on the basis of a consumption-based measure (World Bank, 2003). The dependent variable of logistic regression model was the poverty status of the household, coded 1 if the per capita consumption of the household was below the poverty line (Lek 4,891) and coded 0 otherwise. Logistic regression is recommended over linear regression when modeling dichotomous responses and allows the researcher to estimate probabilities of the response occurring (Hosmer and Lemeshow, 2004).

The set of the explanatory variables chosen as possible determinants of poverty were: age of household head (in years), education level of household head ( $1=$ secondary or higher, $0=$ otherwise), employment status of the household head $(1=$ employed, $0=$ otherwise), gender of the household head $(1=$ male, $0=$ female), household size (total number of members in the household) and residence ( $1=$ urban, $0=$ rural).

\section{Results}

Average age of household head of the sample was 41.6. Majority of household heads (41\%) have age between 30 and 40 years old and followed by them 40 to 50 years old (31\%). The proportion of female headed household was 46 percent. Average household size was 5.02. Forty-five percent of households have less than 4 members followed by families with 5 members (25\%). Average of schooling years of household head was 9.1 . About $36 \%$ of the household heads have completed 8 years of education and only 10\% have completed university. Majority of them lives in urban area (69\%) and have a paid job (71.5\%). Among the employed household heads, $68 \%$ were working in private sector.

Among the sample household heads, $18.6 \%$ declared that they are poor. By comparing the poverty status according to poverty line with poverty perception, resulted that $11.6 \%$ of the poor declared that they are not poor, and $52.4 \%$ of non-poor declared that they are poor. The data of consumption expenditures of the household indicated that the mean of total consumption of the sample was Lek 47,385, respectively Lek 47,224 in urban area, and Lek 47,743 in rural areas. Percentage of households in the sample living in poverty, with per capita consumption below Lek 4,891, was $12 \%$ in urban area and around $36 \%$ in rural area.

The results of the log-linear regression model indicated that the model fits the data well. The regression model is 
statistically significant at $1 \%$ level $(F(6,208)=14.1$, p-value $=0.000)$ and Adjusted-R2 $=26.87$ indicating that $26.87 \%$ of dependent variable was explained by the independent variables of the model. The assumptions of the OLS method were all satisfied. The significant variables were, not surprisingly, household size and residence. It was not expected that the sign of the coefficient of the variable employment status to be negative, because an employed member of household will increase income level of the household and this tendency will directly alleviate poverty.

Table 2. The results of log-linear model of per capita consumption

\begin{tabular}{lc}
\hline Independent variable & Coefficient \\
\cline { 2 - 3 } Age in years of household hear & 0.00065 \\
Education level of household head & 0.06455 \\
Employment status of household head & -0.08972 \\
Gender of household head & 0.04836 \\
Household size & $-0.17657^{*}$ \\
Residence & $0.13622^{*+*}$ \\
Constant & 12.1476 \\
\hline
\end{tabular}

The results show that the coefficient on household size was negative and statistically significant at $1 \%$ level. This means that larger families have a propensity to have lower levels of per capita consumption. Households living in urban areas have a positive coefficient and statistically significant at $10 \%$ level, showing differences in welfare. In terms of household with female head, there is no evidence that female headed households have lower or higher consumption. The age of the household head and the education level were not significant variables in the model. The regression model results do not provide evidence that attaining higher levels of education will increase household welfare.

The robustness of the determinants of poverty was checked by estimating a logistic regression model. The estimated logistic regression model was statistically significant at $1 \%$ level $(\operatorname{LR}$ chi2 $(6)=44.5, p$-value $=0.000)$. Pseudo $\mathrm{R}^{2}$ was 20.9 and the percentage of cases correctly classified was $82 \%$. According to Hair et al. (2009), the classification accuracy should be at least $25 \%$ greater than that achieved by chance. The odds ratio (OR) indicates the ratio of the probability that the household to be poor to the probability that the household to be non-poor.

Table 3. The results of logistic regression

\begin{tabular}{lcc}
\hline Independent variable & Coefficient & OR \\
\hline Age in years of household head & -0.019 & 0.98 \\
Education level of household head & 0.115 & 1.12 \\
Employment status of household head & 1.187 & $3.28^{* *}$ \\
Gender of household head & -0.277 & 0.76 \\
Household size & 0.484 & $1.62^{*}$ \\
Residence & -1.129 & $0.32^{*}$ \\
Constant & -3.381 & \\
\hline
\end{tabular}

Note: * significant at 1\% level, ${ }^{*}$ significant at $5 \%$ level

The results of logistic model indicate that household size, residence and employment status of the household were significant variables, whereas age in years, education level and gender of household head were not significant in explaining the household poverty status. Household size, residence, education level and employment status of household head have odd ratios greater than one, which means that these variables were positively associated with the probability of being poor. On the contrary, age and gender of the household head have odd ratios lower than one, which means that these variables were negatively associated with the probability of being poor. The variable household size was significant at $1 \%$ level, and provided evidence that the larger households were more likely to be poor $(\mathrm{OR}=1.46)$ than others. The residence was significant at $1 \%$ level, and indicated that, urban households were less likely to be poor $(\mathrm{OR}=0.32)$ compared to rural households. The employment status of household head was significant at $10 \%$ level in the logistic model. This means that households with employed heads had more chances $(\mathrm{OR}=3.28)$ to be poor compared to other households. 


\section{Discussion}

The results of two regression models showed that the household size, residence and employment status were the most important determinants of household poverty. Education, age and gender of household head showed no significant relationships with poverty status.

In this study, the age of household head was not significant and was negatively associated with the probability of being poor. This result is consistent with the findings of the multivariate analysis in the study of Achia et al. (2010). The age of the household head was negatively related to the probability of being poor according to Sekhampu (2013). Also, in the report of World Bank (2007) was found negative correlation between age and poverty in Albania. Myftaraj (2011) found that age of household head impacted positively the welfare of the household.

Education level of the household head in this study was not significant to poverty. Education level was negatively related to the probability to be poor, but not significant in the study of Sekhampu (2013). This finding was inconsistent with results of the study of Achai et al. (2010) which concluded that increases in educational attainment of the household head had an important impact on reducing the probability that a household was poor, and Geda et al. (2005), who concluded that higher education level was associated with a lower probability of being poor. Audet et al. (2006) found that the education level of the household's head was a significant factor explaining poverty where lower levels of education indicate higher poverty levels in Albania. In the reports of World Bank $(2003,2007)$ was found that poverty in Albania was negatively correlated with education. Myftaraj (2011) found that households with secondary or higher education level of heads were less likely to be poor.

The employment status of household members is also a key determinant of poverty. The results of this study, indicated that the households with employed heads was more likely to be poor than other households. Ramon et al. (2004) concluded that the employment status of the head of household is important as it determines household income. Sekhampu (2013) found that employment status negatively affected the probability to be poor.

Several studies have discussed the phenomenon of the feminization of poverty, which is said to exist if poverty is more prevalent among female-headed households than among male-headed households. In this study the gender of the household head was not significantly correlated to poverty. This finding was consistent with the World Bank (2007) report; female headed households were not more likely to be poor. Geda et al. (2005) reported that households headed by males have a lower probability of being poor and Mastromarco et al. (2010), found female heads were more likely to be poor.

Household size was an important factor in determining the poverty in this study. Size of household was found not significant when included in the multivariate analysis in the study of Achia et al. (2010). In their study, Audet et al (2006) found that household size affected negatively household expenditure and that large households were more likely to be poor. In the report of World Bank (2007) was found positively association between household size and poverty in Albania, and the same result was found by Sekhampu (2013), Myftaraj (2011), World Bank (2003) and Greda et al. (2001).

Residence of the household was another important determinant of poverty. The findings of this study indicated that urban households were less likely to be poor compared to rural households. This finding was consistent with the finding of Myftaraj (2011), Achia et al. (2010), and Audet et al. (2006). Audet et al. (2006) and Myftaraj (2011) also found that households living in rural zones negatively affected household expenditure.

\section{Conclusions}

Poverty trends in Albania, based on Albania LSMS surveys data analysis, indicated an overall poverty increase due to global financial crisis and the slow-down of economic growth. The increase of the incidence of poverty was higher in urban area.

The results of two econometric models indicated that household size and residence were the factors that influence the welfare of the households in the sample. From the results of log-linear regression model it can be concluded that sample families with higher number of members had lower consumption per capita, and urban households had higher consumption expenditures per capita. From the results of logistic regression model it can be concluded that larger families were more likely to be poor, urban households were less likely to be poor, and surprisingly, households with employed heads were more likely to be poor. Education, age and gender of household head showed no significant relationships with poverty status.

These results have important policy implications for design and implementation of poverty reduction strategies. 
Poverty alleviation efforts should be made to improve the social and demographic characteristics of the households, since the number of the poor is increased in both urban and rural areas. To reduce poverty, attention must be paid to the manufacturing sector, agriculture and tourism.

The findings of this study have some limitations. First, the sample of the households was small and do not included all the regions of Albania. Second, this study examined some of the determinants of poverty. Other factors such as health within the household, education index of the family, household structure, dependent ratio, female-male ratio, number of employed members in the household, house conditions and household assets such as dwelling ownership, land, livestock, etc, were not examined. In future research, these factors can be examined and a large dataset must be obtained.

\section{References}

Achia T, Wangombe A, Khadioli N (2010). A logistic regression model to identify key determinants of poverty using demographic and health survey data. European Journal of Social Sciences, 13(1): 38-45.

Audet, M., Boccanfuso, D., Makdissi, P., (2006). The Geographic Determinants of Poverty in Albania. Groupe de Recherche en Économie et Développement International Cahier de recherche / Working Paper 06-12.

Cuesta J., Nopo H. and Pizzolitto G., (2011) "Using Pseudo Panels to Measure Income Mobility in Latin America", Review of Income and Wealth, Vol.57, No. 2 ,pp.224-246.

European Commission (2013). 2013 Economic and Fiscal Programmes of Albania and Bosnia and Herzegovina: EU Commission's overview and country assessments, Occasional Papers 158, July 2013, ISSN 1725-3209

Fourage D. and Layte R. (2003) "Duration of Poverty Spells of Europe", EPAG Working Papers Number 2003-47.

Geda A., Jong N. , Mwangi K., Mwabu G. (2001) "Determinants of Poverty in Kenya: A Household Level Analysis", KIPPRA Discussion Paper, No.9.

Hair, J.F., Black, W., Babin, B.J., Anderson, R.E. (2009). Multivariate Data Analysis, 7th edition, Prentice Hall. Hosmer D.W. \& Lemeshow S. (2004). Applied Logistic Regression, 2nd ed.

INSTAT and World Bank (2013). Albania: Trends of Poverty: 2002-2005-2008-2012.

INSTAT database: www.instat.gov.al

Mastromarco C, Peragine V, Russo F, Serlenga L, (2010). Poverty, Inequality and Growth in Albania: 2002 - 2005 Evidence, February 2010.

Myftaraj, E. (2011). Empirical estimations of Poverty in Albania. Dissertation, Faculty of Economy, Tirana University, Albania.

Ramon J, Albert G, Collado M.N (2004). Profile and Determinants of Poverty in the Philippines. Statistical Research and Training Center, Philippine National Statistics Office.

Sekhampu, T.J. (2013). Determinants of Poverty in a South African Township, Journal of Social Sciences, 34(2): 145-153 .

World Bank (2003). Albania Poverty Assessment. World Bank Report No. 26213-AL, Washington DC.

World Bank (2007). Albania: Urban growth, Migration and Poverty Reduction: A Poverty Assessment. Report n0. 40071-AL. December 2007. 